\title{
Spinal Hemangioblastoma
}

National Cancer Institute

\section{Source}

National Cancer Institute. Spinal Hemangioblastoma. NCI Thesaurus. Code C155948.

A hemangioblastoma that arises from the spinal cord. It may be associated with von

Hippel-Lindau disease. 